\title{
Pattern of Adverse Drug Reactions of Anticancer Drugs Used in Patients with Non Hodgkin's Lymphoma in A Tertiary Care Hospital
}

\author{
Sam Anbu Sahayam $\mathrm{J}^{1}$, Kulandaiammal $\mathrm{M}^{2}$, Vasanthira $\mathrm{K}^{3}$ \\ ${ }^{I}$ (Department of Pharmacology, Stanley Medical College/ Tamilnadu Dr. MGR Medical University, \\ Chennai, India) \\ ${ }_{2}^{2}$ Department of Pharmacology, Stanley Medical College/ Tamilnadu Dr. MGR Medical University, \\ Chennai, India)
}

\begin{abstract}
:
Introduction: Non Hodgkin's lymphomas are a heterogenous group of malignant neoplasms in which lymphocytes - either B-cell, T-cell, or natural killer (NK) cell origin which have arrested at various stages of differentiation, have acquired ability to clonally proliferate and do not undergo apoptosis in a typical fashion. Tremendous variation exist in its molecular profiles, mode of presentation, natural history and response to therapy.

Settings and design: Retrospective study.

Materials and methods: Adverse reaction pattern of anticancer drugs in patients with Non Hodgkin's Lymphoma in Department of Oncology, Govt. Stanley Hospital, Chennai.

Results: Out of 30 patients receiving CHOP regimen of these drugs, the adverse effects reported in \% were as follows: nausea/vomiting (53.3\%), mucositis (30\%), anemia (20\%), leucopenia (16.67\%),tingling \& numbness(20\%), alopecia (23.3\%), peripheral neuritis (13.3\%). Out of 30 patients receiving $R$-CHOP regimen of these drugs, the adverse effects reported in \% were as follows: nausea/vomiting (63.3\%), mucositis (36.67\%), anemia (30\%), leucopenia (20\%), tingling \& numbness (16.67\%), alopecia (30\%), peripheral neuritis (16.67\%), hematuria(6.67\%), allergic reactions(3.3\%).

Conclusion: When compared with standard CHOP alone, the addition of Rituximab to standard CHOP regimen in Non Hodgkin's lymphoma patients there was a minimal increase in the occurrence of chemotherapy-related adverse events.

Keywords: Non Hodgkin's Lymphoma, CHOP regimen, ADR, CDSCO.
\end{abstract}

\section{Introduction}

An Adverse drug reaction (ADR) is defined by WHO as "A response to a drug which is noxious \& unintended, and which occurs at doses normally used in humans for the prophylaxis, diagnosis or therapy of disease, or for the modification of physiological function" ${ }^{[1]}$.Adverse drug reactions are a global problem which burdens the society. Sometimes the ADRs are so serious \& severe that, the cost needed to control the morbidity \& mortality is more than the cost to treat the actual disease ${ }^{[2]}$. The National Pharmacovigilance Program in India was started with the objectives of monitoring the safety of drugs and creation of an ADR database for the Indian population ${ }^{[3]}$.

Non Hodgkin's lymphomas are a heterogenous group of malignant neoplasms in which lymphocytes either B-cell, T-cell, or natural killer (NK) cell origin and has the ability to proliferate and do not go apoptosis in a typical fashion. Non Hodgkin's lymphoma is the sixth most common cause for cancer in both men and women but shows a male predominance in almost all subtypes. It accounts for $4 \%$ to $5 \%$ of new cases of cancer as well as $3 \%$ to $4 \%$ of cancer related deaths worldwide.

The one-year survival rate is $80 \%$ in for all subtypes of Non Hodgkin's lymphoma. B cell lymphomas represent about $80 \%$ to $85 \%$ of all cases. T cell lymphomas represent about $15 \%$ to $20 \%$ of all cases. NK cell lymphomas are extremely rare.

Non Hodgkin's lymphoma responds to R-CHOP regimen (Rituximab, cyclophosphamide; doxorubicin, vincristine, prednisolone).Relapse cases were managed by salvage chemotherapy with gemcitabine, etoposide and carboplatin. The etiology of most cases of Non Hodgkin's lymphoma is unknown although advances in molecular medicine have provided exciting insights into the biology of Non Hodgkin's lymphoma. 
Sophisticated methods such as cytogenetic translocation, molecular rearrangements by fluorescent in situ hybridization and Polymerase Chain reaction are used in diagnosis.

These drugs themselves can cause adverse drug reactions which shall affect the patients' health. Many of the adverse effects of anticancer drugs are an extension of their therapeutic action, which is not selective for malignant cells but affects all rapidly dividing cells. We did this study to establish the pattern of adverse effects of anticancer drugs in Non-Hodgkin's lymphoma patients and causality assessment and severity scale were done.

\subsection{Study Design And Participants:}

\section{Methods}

We did this retrospective study in department of Medical oncology, Stanley Medical College and Hospital. The case records of patients who completed chemotherapy during 2013 to 2015 were reviewed and the adverse reactions were noted. 30 patients who received CHOP regimen alone and 30 patients who received RCHOP were reviewed.

The eligible patients were both males and females aged 20 to 70 years who received multiple combinations of anticancer drugs as adjuvant or neoadjuvant or palliative chemotherapy. The patients who are receiving drugs for other cancers were excluded from the study. We also exclude patients with past history of gastrointestinal, hematological, hepatic and renal disorders.

This study was conducted after obtaining approval from the Institutional Ethics Committee, Government Stanley Medical College.

Based on the age, sex ,diagnosis, chemotherapy and symptoms given by the patients' statistical analysis was done \& results were obtained. ADRs documented in suspected ADR reporting forms designed by CDSCO and causality assessment was done using Naranjo's scale and severity by modified Hartwig Siegel scale.

The following anticancer drugs were used for Non Hodgkin's Lymphoma ${ }^{[4]}$.

Group I: CHOP regimen given for Non Hodgkin's lymphoma patients ${ }^{[5]}$.

- Cyclophosphamide $1200 \mathrm{mg}$ on day 1

- Doxorubicin $80 \mathrm{mg}$ IV on day 1

- Vincristine $20 \mathrm{mg}$ IV on day 1

- Prednisolone $100 \mathrm{mg}$ per day orally on days $1-5$.

Each cycle is 21 days.

GROUP II: R-CHOP regimen given for Non Hodgkin's lymphoma patients ${ }^{[6]}$.

- Rituximab ${ }^{[7]} 600 \mathrm{mg}$ IV on day 1

- Cyclophosphamide $1200 \mathrm{mg}$ on day 1

- Doxorubicin $80 \mathrm{mg}$ IV on day 1

- Vincristine $20 \mathrm{mg}$ IV on day 1

- Prednisolone $100 \mathrm{mg}$ per day orally on days $1-5$.

Each cycle is 21 days.

Table 1 : Factors associated with increased risk of Non Hodgkin's Lymphoma

\begin{tabular}{|l|}
\hline Immunosuppression \\
\hline Congenital immunodeficiency syndromes \\
\hline Male gender \\
\hline Increasing age \\
\hline Family history of NHL \\
\hline Drugs \\
\hline Immunosuppressive agents \\
\hline Phenytoin \\
\hline Methotrexate \\
\hline Tumour necrosis factor inhibitors \\
\hline Occupational exposures \\
\hline Exposure to herbicides, pesticides, wood dust, epoxy glue, solvents \\
\hline Farming, forestry, painting, carpentry, tanning \\
\hline
\end{tabular}




\subsection{Age distribution}

\section{Results}

Table 2: Age distribution of patients

\begin{tabular}{|l|l|l|l|}
\hline S.No & Age $($ Yrs $)$ & No of Patients & $\%$ of patients \\
\hline 1. & $\leq 30$ & 4 & $6.7 \%$ \\
\hline 2. & $31-40$ & 7 & $11.7 \%$ \\
\hline 3. & $41-50$ & 11 & $18.3 \%$ \\
\hline 4. & $51-60$ & 22 & $36.7 \%$ \\
\hline 5. & $61-70$ & 16 & $26.7 \%$ \\
\hline
\end{tabular}

Table $1 \&$ Figure 1 show the age distribution of the patients with Non-Hodgkin's lymphoma. $6.7 \%$ of patients were in age group $\leq 30$ years, $11.7 \%$ in age group $31-40$ years, $18.3 \%$ in age group of $41-50$ years, $36.7 \%$ in age group 51-60 years \& $26.7 \%$ in age group 61-70 years. More Patients were in the age group 51-60 years followed by $61-70$ years.

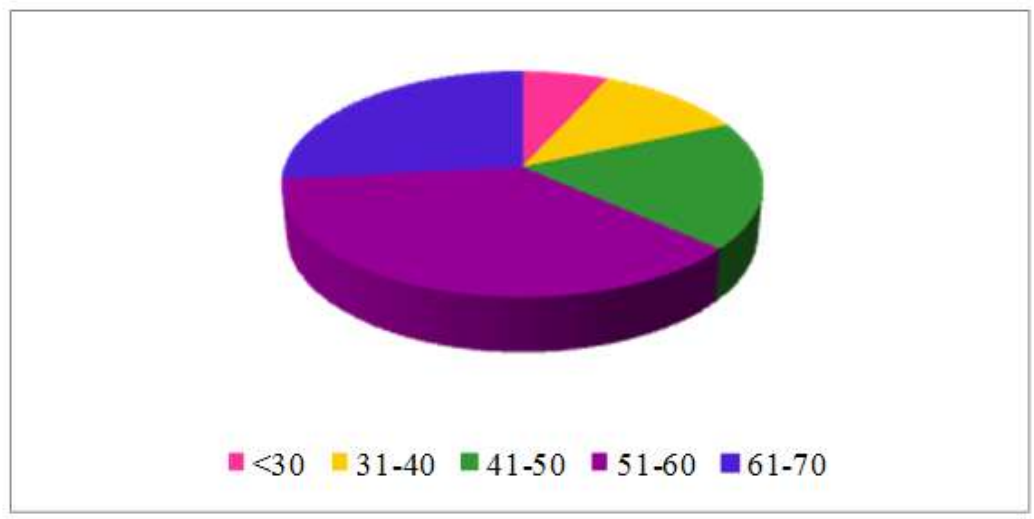

“Fig". 1 : Age distribution

\subsection{Sex distribution:}

Table 3 : Sex distribution

\begin{tabular}{|l|l|l|}
\hline Gender & Group I & Group II \\
\hline Male & 21 & 19 \\
\hline Female & 9 & 11 \\
\hline Total & 30 & 30 \\
\hline
\end{tabular}

\section{Diagnosis}

\section{DIAGNOSIS}

DL B CL [Diffuse Large B Cell Lymphoma]

Mesentric Lymphoma

Nasopharyngeal Lymphoma

Gastric Lymphoma

Follicular Lymphoma - Low grade

Ileocaecal Lymphoma

Burkitt's Lymphoma

Cutaneous T Cell Lymphoma

NK - T Cell Lymphoma

Retroperitoneal Lymphoma

Right testicular lymphoma

Large cell Anaplastic Lymphoma

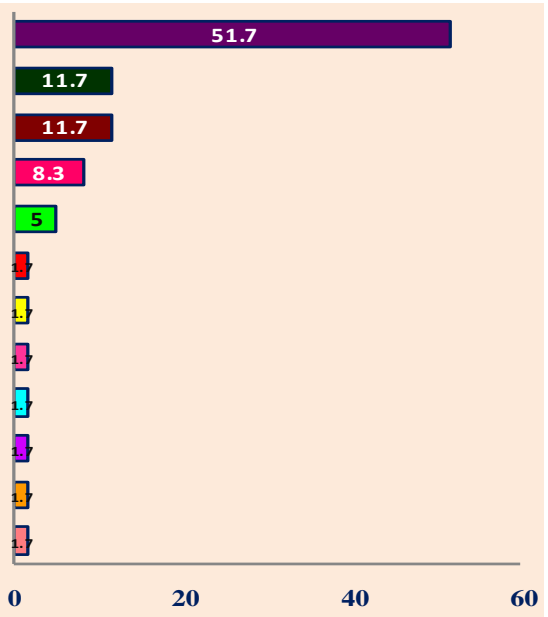


Of the 60 patients majority were DLBCL (Diffuse Large B Cell Lymphoma). ${ }^{[8]}$ followed by mesenteric lymphoma and nasopharyngeal lymphoma.

\section{Pattern of adverse effects}

Table 4: Pattern of adverse effects

\begin{tabular}{|c|c|c|c|c|}
\hline \multirow[t]{2}{*}{ ADVERSE EFFECTS } & \multicolumn{2}{|c|}{$\begin{array}{l}\text { TOTAL No of PATIENTS } \\
(n=60)\end{array}$} & \multicolumn{2}{|c|}{$\%$ OF PATIENTS } \\
\hline & I $(\mathbf{n}=\mathbf{3 0})$ & II $(\mathbf{n}=\mathbf{3 0})$ & I & II \\
\hline Nausea/Vomiting & 16 & 19 & $53.3 \%$ & $63.3 \%$ \\
\hline Mucositis & 9 & 11 & $30 \%$ & $36.67 \%$ \\
\hline Anemia & 6 & 9 & $20 \%$ & $30 \%$ \\
\hline Leucopenia & 5 & 6 & $16.67 \%$ & $20 \%$ \\
\hline Tingling\& Numbness & 6 & 5 & $20 \%$ & $16.67 \%$ \\
\hline Alopecia & 7 & 9 & $23.3 \%$ & $30 \%$ \\
\hline Peripheral neuritis & 4 & 5 & $13.3 \%$ & $16.67 \%$ \\
\hline Hematuria & 1 & 2 & $3.3 \%$ & $6.67 \%$ \\
\hline Fever & 1 & 2 & $3.3 \%$ & $6.67 \%$ \\
\hline Allergic reactions & 1 & 1 & $3.3 \%$ & $3.3 \%$ \\
\hline Epigastric burn & 1 & 1 & $3.3 \%$ & $3.3 \%$ \\
\hline
\end{tabular}

Out of 30 patients receiving CHOP regimen of these drugs, the adverse effects reported in $\%$ were as follows: nausea/vomiting (53.3\%), mucositis (30\%), anemia (20\%), leucopenia (16.67\%), tingling \& numbness (20\%), alopecia (23.3\%), peripheral neuritis $(13.3 \%)$.

Out of 30 patients receiving R-CHOP regimen of these drugs, the adverse effects reported in $\%$ were as follows: nausea/vomiting (63.3\%), mucositis (36.67\%), anemia (30\%), leucopenia (20\%),tingling \& numbness $(16.67 \%)$,alopecia (30\%), peripheral neuritis $(16.67 \%)$, hematuria(6.67\%), allergic reactions $(3.3 \%)$.

Most common adverse effect observed was nausea/vomiting. Next to it were mucositis, alopecia, anemia, tingling \& numbness and peripheral neuritis.

VI. Causality assessment

Table 5: Causality assessment of adverse drug reaction

\begin{tabular}{|l|l|l|}
\hline ASSESSMENT CATEGORY & NO.OF PATIENTS & PERCENTAGE \\
\hline CERTAIN & 0 & 0 \\
\hline PROBABLE & 4 & $6.7 \%$ \\
\hline POSSIBLE & 56 & $93.3 \%$ \\
\hline Total & 60 & $100 \%$ \\
\hline
\end{tabular}

VII. Severity assessment

Table 6: Severity assessment of adverse drug reactions

\begin{tabular}{|l|l|l|}
\hline ASSESSMENT CATEGORY & NO.OF PATIENTS & PERCENTAGE \\
\hline Mild & 57 & $95 \%$ \\
\hline Moderate & 3 & $5.0 \%$ \\
\hline Severe & 0 & 0 \\
\hline Total & 60 & $100 \%$ \\
\hline
\end{tabular}

\section{Discussion}

The age distribution of the patients with Non-Hodgkin's lymphoma. $6.7 \%$ of patients were in age group $\leq 30$ years, $11.7 \%$ in age group $31-40$ years, $18.3 \%$ in age group of $41-50$ years, $36.7 \%$ in age group 51-60 years \& $26.7 \%$ in age group 61-70 years. More Patients were in the age group 51-60 years followed by $61-70$ years.

Our findings show that the adverse effects most commonly observed in both CHOP regimen and RCHOP regimen was nausea and vomiting. In CHOP regimen following nausea and vomiting (53.3\%), in decreasing order of frequency are mucositis (30\%), anemia (20\%), leucopenia(16.67\%), tingling \&

DOI: $10.9790 / 0853-150802104108 \quad$ www.iosrjournals.org $\quad 107 \mid$ Page


numbness(20\%), alopecia (13.3\%), peripheral neuritis $(13.3 \%)$. In R-CHOP regimen following nausea and vomiting $(63.3 \%)$ the adverse effects noted were mucositis $(36.67 \%)$, anemia (30\%), leucopenia(20\%),tingling \&numbness (16.67\%), alopecia (30\%), peripheral neuritis $(16.67 \%)$, hematuria(6.67\%), allergic reactions $(3.3 \%)$.

The sex distribution of the patients in CHOP regimen (21 male patients vs 9 female patients : 40\%), and in R-CHOP regimen (19 male patients vs 11 female patients).

The percentage of GIT adverse effects like nausea and vomiting, mucositis in group I is less than observed in Group II. Nausea occurs by both central action on the CTZ and peripheral action on the GIT. The dominant receptors in the $\mathrm{CTZ}$ are $5-\mathrm{HT}_{3}$ and $\mathrm{D}_{2}$. As $5 \mathrm{HT}$ receptors in the brain are involved in the mechanism of acute onset vomiting, ondansetron helps in its prevention. Mucositis ${ }^{[11]}$ occurs mainly due to decrease in the rate of renewal of GI mucosal lining.

The neurological adverse effects like peripheral neuritis is less in Group I but tingling and numbness sensation over body is more in Group I.

Hematological adverse effects like anemia, leucopenia are less in Group I. Pre-treatment values of complete hemogram were taken for every patient before each cycle and post treatment assessment was done only if clinically indicated. Urinary symptoms like hematuria is also less in group I.

There were no serious adverse effects observed in Group I and Group II. Causality assessment was done with Naranjo's scale and most of the adverse reactions were found to be possible (93.3\%) and a few are found to be probable $(6.7 \%)$.

Severity assessment was done with Hartwig-siegel scale which shows majority adverse reactions (95 $\%$ ) are mild compared to $5 \%$ of patients are assessed as moderate.

Most of the adverse drug reactions were not preventable because of their poor predictability and poorly understood causative mechanisms. Common adverse reactions like nausea and vomiting can be effectively controlled by adequate pre- medication. Hence, the physician should anticipate and counsel the patient adequately prior to the chemotherapy. Most of the adverse reactions were less severe. So, there was no need to change or withhold the drug for milder adverse effects.

\section{Conclusion}

The study revealed that when compared with standard CHOP alone, the addition of Rituximab to standard CHOP regimen in Non Hodgkin's lymphoma patients there was a minimal increase in the occurrence of chemotherapy-related adverse events.

Anticancer drugs have a narrow therapeutic index. Many of the adverse effects of anticancer drugs are an extension of their therapeutic action, which is not selective for malignant cells but affects all rapidly dividing cells. Most of the adverse drug reactions in this study were mil and ameliorated by therapy. Early detection of the drug toxicity helps to modify the dose or drug regimen to minimize the toxicities. This study also emphasizes the need to improve pharmacovigilance awareness among physicians in order to improve the pharmacovigilance system in India.

\section{References}

[1]. S.K.Gupta. Text book of Pharmacovigilance. $1^{\text {st }}$ edition $\mathrm{p}-1-2$

[2]. Smith, D.L 1993. The effect of patient non-compliance on health care costs. Med Interface. 6,74-84

[3]. Adithan C. National pharmacovigilance programme. Indian J Pharmacology. 2005; 37:347.

[4]. Coiffier B, Lepage E, Briere J, et al. CHOP chemotherapy plus rituximab compared to CHOP alone in elderly patients with diffuse large cell lymphoma.NEJM.2002:346:235- 242.

[5]. Feugier P, Van Hoof A, Sebban c, et al. Long-term results of the R-CHOP study in the treatment of elderly patients with diffuse large B-cell lymphoma: a study by the group d'Etude des lymphomes de l'adulte. J Clin Oncol. 2005:23(18):4117 - 4126.

[6]. Fisher RI, Gaynor ER, Dahlberg S, et al. Comparison of a standard regimen (CHOP) with three intensive chemotherapy regimens for advanced Non-Hodgkin's lymphoma. NEJM 1993:328:1002-1006.

[7]. Hainsworth JD, Litchy S, Burris HA, et al. Rituximab as first line and maintenance therapy for patients with indolent NonHodgkin's lymphoma. J Clin Oncol 2002:20:4261-4267.

[8]. International Non Hodgkin's lymphoma prognostic factors project. A predictive model for aggressive Non Hodgkin's lymphoma. NEJM 1993:329:987-994.6. Sehn LH, Donaldson J, Chhanabhai M, et al. Introduction of combined CHOP plus rituximab therapy dramatically improved outcome of diffuse large B-Cell lymphoma in British Columbia. J clin Oncol 2005: 23:5027-5033.

[9]. Naranjo CA, Busto U, Sellers EM, Sandor P, Ruiz I, Roberts EA, et al. A method for estimating the probability of adverse drug reactions. Clinical Pharmacology Therapeutics. 1981;30:239-45.

[10]. Hartwig SC, Siegel J, Schneider PJ. Preventability and severity assessment in reporting adverse drug reactions. Am J Hosp Pharm. 1992;49:2229-32.

[11]. Keefe DM, Schubert MM, Etling LS et al.Updated clinical practice guidelines for the prevention and treatment of Mucositis. Cancer 2007; 109:820-831. 